DOI: $10.17805 / z p u .2016 .1 .3$

\title{
О методологическом кризисе общественной науки в контексте вызовов современности
}

\author{
С. Б. БУЛЕКБАЕВ
}

(КАЗАХСКИЙ УНИВЕРСИТЕТ МЕЖДУНАРОДНЫХ ОТНОШЕНИЙ И МИРОВЫХ ЯЗЫКОВ

\author{
ИМ. АБЫЛАЙ ХАНА, Г. АЛМА-АТА)
}

Для общественной науки проблемы методологии всегда представляют чрезвычайно важную задачу. Особенно эта значимость возрастает в современном мире, когда глобализационные вызовы и экономические кризисы не только кардинально меняют общество, но и наглядно демонстрируют слабость объяснительного потенциала многих традиционных теорий. Отсюда чрезвычайно важным представляется анализ теоретико-методологической базы современной общественной науки.

В статье обосновывается мысль о том, что причины современного системного кризиса объясняются тем, что многие фундаментальные понятия общественной науки не совсем адекватно отражают изменившуюся реальность, в частности кризисные процессы и явления в области мировой экономики, политики, межэтнических отношений. Общественные науки часто не способны не только предсказать, но и объяснить причины и сущность этих процессов.

Согласно мнению автора слабость объяснительного потенциала общественной науки состоит в том, что она до сих пор основывается на ньютоно-картезианской метапарадигме, которая, в свою очередь, базируется на законах макромира, в то время как современный мир стал фактически похожим на микромир.

Отсюда необходимы пересмотр и уточнение существующего категориального аппарата и, соответственно, поиск и разработка новой метапарадигмы мышления.

Ключевые слова: методология общественных наук; глобализация; объяснительный потенциал; парадигма; метапарадигма; мировая экономика; мировая политика

\section{ВВЕАЕНИЕ}

$\mathrm{M}$ ногие ученые, анализирующие причины современного системного кризиса, приходят на удивление к одинаковым выводам, суть которых состоит в том, что многие современные фундаментальные понятия о реальности, о сознании, о человеке, об обществе и других процессах на сегодня не совсем адекватно отражают реальность. Здесь имеется в виду то, что современный мир за последние несколько десятилетий изменился столь радикально, что вполне закономерно многие старые понятия потеряли в значительной степени свой объяснительный потенциал и методологическую состоятельность. Понимание этого факта сегодня становится повсеместным. Это и «цветные революции», объяснение и понимание которых выходит за рамки не только истматовских представлений, но и других существующих социальных теорий и парадигм. Это можно видеть и в области международных отношений, когда некоторые события нельзя объяснить в рамках привычных понятий и представлений. К примеру, события, связанные с присоединением или захватом Крыма Россией, или оценки и объяснения событий, которые происходят на юго-востоке Украины.

Также, на наш взгляд, до сих пор нет удовлетворительного понимания природы и сущности глобального мирового системного кризиса. Аействительно, лучшие умы экономической науки до сих пор не только не способны предупредить, но и даже сущностно объяснить истинные причины, регулярно сотрясающих мир экономических кризисов. Также не очень убедительны и внятны объяснения причин многочисленных этнических и религиозных конфликтов, участившихся за последнее время, не говоря уже о кризисе культуры и духовных ценностей. Все эти факты, на наш взгляд, нагляд- 
но демонстрируют кризис современной общественной науки, ее мировоззренческой и методологической базы. Этот факт признают уже многие. Однако в данном случае парадоксально другое, что на этом признании в основном ученые останавливаются. Если и делаются попытки объяснить причины кризиса в своей предметной области, то это, как правило, ограничивается методологическим инструментарием своей науки, признанием слабости ее объяснительного потенциала, в то время как данная проблема, на наш взгляд, выходит за рамки методологической базы отдельной общественной науки. И связана она в конечном счете с более общей проблемой, с так называемой общей метапарадигмой современной науки, которая на сегодняшний день устарела и не соответствует требованиям современной науки. Аля пояснения этого утверждения сделаем небольшой вводный исторический экскурс.

Начнем с того, что с 1970-х годов научным сообществом все более настоятельно «осознается тот факт, что европейская цивилизация претерпевает глубокую культурную трансформацию, состоящую в “смене парадигм”» (Концепция целостности ... , 1987: 187), которая выражается в пересмотре идей и ценностей западной культуры, доминирующих в мире на протяжении последних столетий. Это безграничная «вера в научный метод как единственно обоснованный подход к реальности; противопоставление сознания и материи; взгляд на жизнь в обществе как на конкурентную борьбу за выживание, вера в неограниченный материальный прогресс на основе экономического и технологического роста, взгляд на природу как на механическую систему» (там же), а также эгоистический принцип личного счастья.

Аля того чтобы уяснить необходимость смен этих парадигм, отметим, что парадигмой в науке называют общепринятые теории и способы научного исследования. По мнению известного английского ученого П. Рассела, «парадигма - это набор допущений, которыми оперирует та или иная конкретная наука. Примерами парадигм могут служить квантовая теория, механика Ньютона, теория хаоса, дарвиновская теория эволюции и психоаналитическая модель подсознания. Со временем одна парадигма сменяет другую. <..> Подобные радикальные изменения во взглядах на мир можно наблюдать... по сути, во всех науках (Рассел, 2005: 37-38). Рассел отсылает читателя к известной книге Т. Куна «Структура научных революций» (Кун, 1975), в которой раскрываются структура и механизм перехода от одной парадигмы к другой, и отмечает, что смена парадигм «в науке случается тогда, когда общепринятая парадигма сталкивается с аномалией - феноменом, который невозможно объяснить в рамках существующего мировоззрения» (Рассел, 2005: 38).

Анализируя проблему смены парадигм в науке, П. Рассел считает, что созданная Куном модель «революций» в науке или модель смены парадигм не следует ограничивать отдельными научными дисциплинами. Более того, по его мнению, на ее основе следует рассмотреть в принципе все западное научное мировоззрение в целом. В нем, т. е. в западном мировоззрении, все «научные парадигмы основываются на следующем допущении: реальность - это физический мир; пространство, время, материя и әнергия - фундаментальные составляющие реальности. <..> Поскольку на этом допущении основаны все наши научные представления о мире, оно есть нечто большее, чем просто парадигма; это метапарадигма - иначе говоря, парадигма, лежащая в основе всех парадигм. Аанная метапарадигма настолько удачно объясняет почти любое явление материального мира, что она едва ли когда-нибудь подвергалась сомнению. И только обратившись к нематериальному миру сознания, мы начинаем находить в ней слабые места» (там же: 46-47). Здесь мы имеем в виду то, что наука 
«демонстрирует свое бессилие, когда дело доходит до человеческих чувств» (там же), а в последние же десятилетия и в объяснении и понимании современных глобализационных процессов.

Причину этого П. Рассел видит в общепринятой научной модели: «Мы знаем, что элементарные частицы соединяются в атомы, из которых, в свою очередь, образуются молекулы, - такова модель формирования физических объектов. Нечто подобное можно сказать и о живой клетке. В основе АНК, белков и аминокислот - все те же атомы. Эта модель позволяет описывать даже человеческий мозг, несмотря на всю его невероятную сложность» (там же: 47-48). Однако такая модель, с точки зрения ученого, для описания сознания не годится, так как «сознание не материально; материя не обладает сознанием. И посему упомянутая выше метапарадигма не позволяет объяснить, что такое сознание» (там же: 48). И вполне закономерно, что в рамках этой модели ни одна из научных теорий «не дает ответа на следующий вопрос: как вообще нечто столь нематериальное, как сознание, может возникнуть из чего-то столь несознательного, как материя? Алинная череда неудачных попыток объяснить феномен сознания заставляет предположить, что наука, попросту говоря, идет по неверному пути. Все научные теории сознания исходят из того, что этот феномен вторичен по отношению к физическому миру, который описывается в категориях пространства, времени и материи. Это основополагающее допущение если и подвергается сомнению, то крайне редко. Отсюда стремление все более сложными способами приспосабливать аномалию сознания к нормативу материалистического мировоззрения» (там же: 51 ).

Здесь, по мнению П. Рассела, нужно, «вместо того, чтобы пытаться объяснить феномен сознания в терминах материалистического естественно-научного мировоззрения... сформулировать иную метапарадигму» (там же), которая в отличие от ньютонокартезианской метапарадигмы дает более широкую основу для понимания феномена сознания и которая, как выясняется сегодня, имеет информационно-полевую природу. Если принять эту точку зрения, то сознание гораздо легче объясняется терминами квантовой механики, чем понятиями традиционной философии или психологии. Что, собственно, и происходит в области современной трансперсональной психологии, которая рассматривает человека не только как биосоциальное явление, но и как информационно-полевое образование. Только в контексте последнего можно объяснить и понять многие явления из области сознания, которые игнорировались ранее традиционными представлениями о сознании. К примеру, такие как паранормальные или экстрасенсорные явления, природа идеального и т. п. В этих науках согласно выдающемуся психологу современности С. Грофу осуществляется переход от ньютоно-картезианской картины мира к новой. И эти открытия, по его мнению, в «состоянии полностью перевернуть наши представления о человеческой психике, ее патологии и перспективах лечения. Некоторые из этих данных по своей значимости выходят за рамки психологии и психиатрии и бросают вызов всей ньютоно-картезианской парадигме, лежащей в основании западной науки. Они могут радикально изменить наше понимание человеческой природы, культуры и истории, да и самой реальности как таковой» (Гроф, 1992).

Однако в отличие от вышеуказанных наук т. е. неклассической физики и трансперсональной психологии, остальные, особенно общественные науки, только сегодня начинают осознавать, что они вышли на новый, более сложный уровень реальности, связанный со сложнейшими глобализационными, информационными, коммуникацион- 
ными процессами, которые в совокупности создали новую более сложную и более взаимосвязанную мирохозяйственную систему современного общества. Соответственно этим процессам и отношениям сегодня в современном мире сложилась и новая система политических, экономических и международных отношений, сложилась их новая международная архитектура. Отсюда понятны слабость или исчерпание объяснительного потенциала старых универсальных парадигм и понятий для объяснения этих новых и очень сложных общественных процессов. Говоря иначе, современный мир оказался значительно богаче и разнообразней отраженного во многих существующих общественных теориях и экспертных прогнозах. Сегодня процессы мировой политики оказались более похожими на процессы микромира или мегамира, поэтому попытки объяснять такие процессы на уровне макромира, т. е. более простой ньютоно-картезианской метапарадигмы, однозначно показывают свою неполноту и недостаточность.

В то же время в этих науках, на наш взгляд, до сих пор нет глубокого понимания необходимости новой метапарадигмы науки и новой метапарадигмы мышления. Нет осознания того, что для объяснения и понимания новых особенностей и тенденций развития мировой политики и экономики необходима новая метапарадигма всей науки, что только на ее основе возможна выработка новых теорий и методологий. Аругими словами, сегодня для научного сообщества становится совершенно очевидным, что трансформация социального и индивидуального бытия в условиях современного информационного общества должна сопровождаться изменением методологических стратегий исследования всех сторон жизни социума, которое, в свою очередь, логично влечет за собой пересмотр содержания и функций категориального аппарата философии.

В то же время необходимо осознавать, что совершенствование категориального аппарата и методологического инструментария многих наук ограничено в конечном счете предельными основаниями, заложенными метапарадигмой современной науки и ее метапарадигмой сознания. В данном случае смирительной рубашкой современных общественных наук, сковывающей их объяснительный потенциал, по мнению С. Грофа, являются лежащая в основании этих наук старая ньютоно-картезианская метапарадигма науки и традиционная метапарадигма сознания, которая в отличие от неклассической физики и трансперсональной психологии в этих науках до сих пор не преодолена. Здесь имеется в виду, что сегодня в отличие от упрощенного видения мира с позиций линейного мышления нелинейность является фундаментальной характеристикой природного и социального мира как открытой самоорганизующейся системы и предполагает непрерывность выбора альтернатив ее развития. Нелинейная система обязательно многомерна, многовариантна и не поддается классически-линейным методам описания, что, в свою очередь, порождает потребность в выработке нелинейных методов. Отметим, что методология решения эвристических проблем в нелинейных средах получила название нелинейного мышления. Согласно этой системе мышления главную роль в мире играют неустойчивость и неравновесность, случайность; поведение нелинейных процессов вариативно и однозначно непредсказуемо; порядок может возникать из хаоса спонтанно; нелинейное мышление отрицает однозначный детерминизм. И это чередование с точки зрения нелинейного мышления, т. е. хаоса и порядка, случайности и необходимости, дифференциации и интеграции, является универсальным принципом развития и самоорганизации природного и социального мира. 
Аругой особенностью современного познания является то, что в нем объектами исследования наряду с традиционными предметами реальности, объективной и субъективной, или процессами их взаимодействия важнейшим становится третий вид реальности - это виртуальность, которая как особый вид реальности обладает определенными свойствами и параметрами существования, диктует особые формы поведения, общения, деятельности и в конечном счете оказывает обратное воздействие на человека. И к тому же вполне обоснованно порождает необходимость поиска новой методологии и мировоззренческого обоснования современных процессов единства трех видов реальности.

Отсюда, по мнению некоторых ученых, названные особенности современной познавательной реальности наглядно указывают по меньшей мере на два новых обстоятельства. Первое - традиционные «классические» установки стереотипы, ориентации в области объяснительных схем и методов (например, ориентация на полноту и всеохватность отображения объекта, линейную причинность, исключение субъекта в процессе познания, т. е. полную объективность) уступают место новым (например, ориентации на создание сложного объекта как эффективно проявляющей себя целостности, на обеспечение его надежного и устойчивого функционирования, принятие разных точек зрения как допустимых, понимание, что все имеет свою полярность, и видение любой проблемы, любого события как с одной, так и с противоположной стороны). Второе обстоятельство показывает, что определяющим современное мировоззрение и доминирующим в нем становится ныне взгляд на мир не через отслеживание отдельной логической цепи событий, а через спектр гипотез о происходящем. Это становится самодовлеющим и в стремлении к пониманию множества как самосогласующегося ансамбля, и в создании тех или иных сложных формирований - производственного или общественного объединения, сообщества государств, геополитического союза, корпорации, кооперации.

Вне осознания этих новых реальностей в области как общественной практики, так и познавательной деятельности мир закономерно будет сталкиваться с серьезнейшими проблемами. Особенно это наглядно видно в области современной мировой экономики и политики, где старые понятия не соответствуют изменившимся новым процессам и реалиям. Начну этот экскурс с анализа основополагающих понятий мировой политики, где за последние десятилетия произошли новые качественные изменения. Важной особенностью современных международных отношений в отличие от прошлого стало то, что в этой области уже значительно возросло число мировых игроков, возникди новые интересы, расширились варианты возможных действий и соответственно этому изменились качество и количества необходимой для этих действий информации. Также сегодня чрезвычайно быстро меняются не только соотношения геоэкономических и геополитических факторов, но и условия взаимодействия государственных и негосударственных (трансграничных) политических акторов. Отмечая эти трансформации, российский ученый И. В. Следзевский пишет: «Новые мировые игроки - глобальные ТНК, мегаполисы, общественные и культурные движения (всевозможных форм, оттенков и направлений), неправительственные организации, религиозно-фундаменталистские течения, международные криминальные сети, экстремистские подпольные организации и структуры - действуют на ином поле мировых отношений, чем поле государственных (национальных) интересов и обязательств, гражданского согласия и выстроенных в определенной логике межгосударственных отношений. В этом расширяющемся пространстве свободы от ограничений уже 
не действуют так жестко, как прежде, правила, связанные со смысловыми образами и конструктами “национальный интерес”, “национальный суверенитет”, “национальная территория”, зато действуют неправовые (“теневые”) принципы быстрой максимизации выгоды, анархичные правила определения собственных интересов и целей в соответствии с типом игры, в которую эти структуры, движения и организации включены в конкретной ситуации и в каждый данный момент времени» (Следзевский, 2011: 145).

Как видно из вышеизложенного, необходимость переосмысления и уточнения многих фундаментальных понятий мировой политики и, соответственно, учета этих изменений в принимаемых решениях и практических действиях на сегодняшний день совершенно очевидна. На наш взгляд, в новом переосмыслении также нуждаются и понятия, связанные с объяснением и пониманием так называемых цветных революций, или запланированных хаосов, которые произошли недавно в Восточной Европе, странах СНГ и которые сокрушительно прокатились в последние годы на Ближнем Востоке и севере Африки. К их числу можно отнести и события, которые происходят на юго-востоке Украины. Имеются в виду захват власти участниками Майдана, переход Крыма к России на основе так называемого референдума. И наконец, братоубийственная война, которая сегодня происходит на Украине. Война между украинцами и русскими, т. е. между славянами, которые всегда считали себя братьями.

Все эти события и процессы сегодня ясно показали, как мы отметили выше, несостоятельность не только истматовских представлений о развитии современного общества, но и слабость объяснительного потенциала также многих других известных универсалистских парадигм. Аействительно, в реальности ни одна из современных теорий, претендующих на однозначные и законченные трактовки исторического процесса, не оказалась способной не только предугадать, но даже ясно объяснить суть происходящих процессов (Митрошенков, 2011).

Отсюда очень важной и сложной задачей общественной науки является необходимость осмысления и трактовки ряда понятий, в частности, из области международного права в контексте событий, которые происходят на Украине. Здесь, видимо, речь должна идти не только о прецеденте, связанном с переходом или захватом Россией Крыма или событиями на юго-востоке Украины, а в принципе о необходимости пересмотра всей системы международных отношений, международного права, принципа незыблемости границ, суверенитета и территориальной целостности, соблюдения международных договоров и т. п. Сегодня в мировой политике проходят процессы, которые фактически разрушают или, точнее, уже разрушили сложившуюся систему международных отношений и международного права. Опасность современной ситуации не только в том, что Россия пересматривает устоявшуюся систему международных отношений, а в том, что пример России в области пересмотра системы международных отношений и права в последние годы не единичен. Это и позиция США в Ираке и Афганистане, это и позиция НАТО и стран Евросоюза в отношении Косова и Аивии. Этот печальный список нарушения международного права, к сожалению, можно продолжить.

На наш взгляд, важной причиной разрушения сложившейся системы международных отношений помимо многих других является создание однополярного мира. Имеется в виду, что если до разрушения социалистической системы вся система международного права и безопасности базировалась на паритете двух мировых систем, то сегодня он нарушен. Если раньше существовал коммунистический фундаментализм и 
рыночный фундаментализм, то сегодня доминирует лишь один. Это рыночный фундаментализм со всей его системой ценностей и приоритетов. По мнению известного финансиста Аж. Сороса, этот фундаментализм сегодня представляет уже бо́льшую опасность открытому обществу, чем тоталитарная идеология. Крупнейшим недостатком современной «системы мирового капитализма является тот факт, что она позволила рыночному механизму и мотиву получения прибыли проникнуть во все сферы деятельности, даже туда, где им нет, по существу, места» (Сорос, 1999: XX). Вторым недостатком Сорос считает нестабильность и непредсказуемость, внутренне присущие капитализму, особенно финансовым рынкам, в том смысле, что рыночная ситуация в мире складывается из многих тысяч слагаемых, которые практически невозможно учесть, так как это, как правило, является итогом, результирующим десятков тысяч факторов, которые в принципе невозможно учесть. В рыночные отношения вступают миллионы людей, каждый имеет различный капитал, разные способности, разную информацию, разные связи и т. п. Это невообразимо большая информация, которую не способен самый современный и самый большой в мире компьютер собрать и обработать. Поэтому и невозможно точно предсказать, как в естественных науках, что последует в дальнейшем. Здесь можно говорить лишь о некоторых общих особенностях и тенденциях вероятного развития мировых процессов. Поэтому в точном смысле нет экономической науки, как считал великий рыночник Ф. Хайек (Хайек, 1992). Возможно, в силу этих особенностей рыночной системы регулярно происходят разные экономические кризисы, которые не могут предвидеть даже самые выдающиеся экономисты мира. Из всего этого можно сделать лишь такой вывод: рынок - это комплексная система, которая объединяет в себе не только макро- и микроэкономические показатели, но и результаты взаимодействий людей на различных уровнях. То есть при ее анализе и изучении необходимо основываться не только на объективных и рациональных показателях и расчетах, но и на субъективных, учитывать психологию, мнение и настроение людей, как это делается в теории волн Элиота. По крайней мере, до сих пор более успешного инструментария для анализа рынка не существует. По сути, как считает финансовый аналитик C. Аемура, «это теория поведения толпы, так называемая социодинамика. Толпе свойственны заблуждения или мании. Рынки, с точки зрения толпы, абсолютно нелогичны. Современная экономика построена на том, что все инвесторы являются рациональными объектами, то есть все их действия рациональны: исходя из той информации, которой они обладают, они принимают рациональные решения. Так вот толпа или экономические агенты ведут себя иррационально...» (Рубль пошел в последний путь, 2014: Электронный ресурс). Как мы отметили выше, именно об этом говорит и Ф. Хайек.

При этом также не всегда учитываются западными экономистами социально-экономические последствия структурного перекоса в развитии мирового капитализма. Здесь имеется в виду то, что с середины 70-х годов в мировой экономике, как известно, главную роль стали играть транснациональные корпорации и транснациональные банки, которые, исходя из основного принципа рынка - получение максимальной прибыли, стали закрывать предприятия на Западе и переносить их в страны с дешевой рабочей силой (Китай, Юго-Восточная Азия, Аатинская Америка, страны Карибского бассейна и т. А.). Эти изменения привели к незапланированным результатам и непредвиденным последствиям, т. е., с одной стороны, средний класс потерял миллионы рабочих мест, которые отдали развивающим странам, а с другой стороны, в развитых 
странах в основном прирост рабочих мест стал происходить в непроизводственной сфере. Развитые страны стали мало производить товаров. Процент безработных стал катастрофически увеличиваться. Короче говоря, такие особенности развития западного капитализма породили в своих же странах очень сложные задачи, решение которых на современном этапе представляет большую проблему для западных экономистов и политиков.

Еще одной важной особенностью современного капитализма является то, что из всех форм капитала доминирующим на сегодняшний день является финансовый капитал. Сегодня на международной арене самым глобальным рынком стал финансовый (Моисеев, 2006: 57-68). Как пишет А. А. Моисеев, «если в 1990-1998 гг. валовой мировой продукт и объем торговли в мире выросли на несколько процентов, то стоимость сделок с ценными бумагами увеличилась почти на два порядка. Благодаря развитию телекоммуникационных технологий круглые сутки многомиллиардные суммы мгновенно перебрасываются из одной части мира в другую. Современная международная финансовая система оказалась весьма эффективной в условиях компьютеризации и либерализации валютно-финансовых отношений на международном уровне. <...> За короткий исторический период в товарно-денежные отношения международного финансового рынка были вовлечены все регионы и сферы человеческой деятельности, изменены пропорции и расстановка сил между государствами, корпорациями, изменились соотношения между политикой и экономикой, финансами и производством, конкуренцией и научно-техническим прогрессом. Быстрое распространение финансовой информации по всему миру благодаря Интернету, непрерывное движение частного капитала с помощью всевозможных финансовых инструментов: ценных бумаг, акций предприятий, паевых фондов, товарных фьючерсов и пр., деятельность финансовых фондов и бирж, которые практикуют займы под залог ценных бумаг и игру на валютных курсах, действительно носят глобальный характер. Вместе с тем, обостряется опасность мировой капиталистической системы, которая в начале XX в. была названа В. Парето экономикой “финансовых пузырей”. Поскольку финансовые спекуляции становятся более привлекательными, чем любая производственная деятельность, то количество финансовых сделок растет неизмеримо быстрее числа реальных товарных соглашений, что в конечном итоге приводит к глобальному финансовому кризису. Первым таким стал азиатский финансовый кризис 1997-1998 гг.» (Моисеев, 2015: 58). Все чаще отмечается, что все эти негативные процессы ставят под угрозу «целостность культур и суверенитет государств» (Аннан, 2000: 11).

В контексте вышеуказанных тенденций в области мировой экономики коренным образом меняются также роль и функции национального государства. К. Б. Берентаев пишет: «В мирохозяйственной системе возрастающую роль начинают играть новые акторы, транснациональные силы - ТНК и ТНБ, международные правительственные и неправительственные организации, которые оказывают определяющее влияние на внешнюю и внутреннюю политику суверенных государств, особенно слабых и малых. Транснациональные силы уже разрушили национальный суверенитет в прежнем понимании. Структуры ТНК “вкрапливаются” в экономическое пространство всех стран. Экономическую, научно-техническую, промышленную и структурно-инвестиционную политику слабых стран начинает формировать не национальное правительство, а транснациональные силы. В своих сферах на проводимую внутреннюю политику оказывают воздействие и межгосударственные, и международные институты. 
В этих условиях максимально возможное сохранение национального суверенитета слабых и небольших стран объективно требует образования самодостаточных региональных объединений, способных противостоять односторонней глобализации. Это объективный процесс, связанный с тем, что национальные границы небольших госуАарств являются слишком узкими» (Берентаев, 2013: 121).

Аругими словами, в современном мире под влиянием и воздействием могущественных внешних сил в мире практически сформировалась «новая архитектура мирового сообщества, в которой область деятельности традиционных национальных государств существенно сузилась, а принятие решений на национальном уровне все чаше и чаще происходит под прямым влиянием и в интересах новых акторов мирового сообщества» (там же: 125). Поэтому «ни одна национальная экономика уже практически не может развиваться без самого активного участия в мирохозяйственных процессах» (там же).

Отсюда «переосмысление фундаментальных политэкономических категорий, таких как нация, государство, национальные интересы, национальный суверенитет, нормы международного права и др.» (там же: 176), в современной новой реальности, вызванное глобализационными и информационно-коммуникационными процессами, которые видоизменили современный капитализм, придав ему новые особенности. Как отметил Аж. Сорос, из всех видов капитала в современном капитализме главным на сегодняшний день является финансовый капитал. И на международной арене вполне закономерно самым глобальным рынком стал финансовый. Эти фундаментальные процессы мировой экономики, конечно же, не могли не повлиять на международные процессы, но и вполне естественно создали новую архитектуру мирового сообщества, анализ которой становится для современной общественной науки чрезвычайно актуальным. Особенно важно осмысление общественных процессов в контексте новейших трансформаций общественной жизни, пересмотр и уточнение категориального аппарата, а точнее, разработка новой методологии исследования этих новейших процессов. В контексте данного утверждения, на наш взгляд, будет уместным привести результаты «мозгового штурма», организованного газетой The Wall Street Journal, 18 групп молодых лидеров по трем критическим вопросам относительно продолжающего кризиса в 2009 г. Вопросы были такие: «Какая самая разрушительная ошибка политики приводила к кризису?», «Какой регулирующий отказ произвел наибольший системный удар?», «Где произошел наибольший удар по рынку?» (Иноземцев, 2008: Электронный ресурс).

Ответы различных групп в целом можно свести к следующим факторам, которые, по мнению молодых аналитиков, ответственны за расстройство мировой финансовой системы:

- ошибочная вера, что рынки могут саморегулироваться и эффективно исправить себя, а также отказ принять во внимание неизбежные сопутствующие разрушения;

- слишком много не обеспеченных ничем легких денег было предложено на долгосрочном основании, необузданно занижена была цена риска, особенно когда премия риска падала почти до нуля;

- почти религиозная вера в математическое моделирование, основанное на сомнительной выборке данных, которые в конечном счете заменяли здравый смысл;

- отказ давать полное раскрытие рисков, неспособность мировой финансовой системы избежать глобальной оплошности, когда однажды эти риски реально появились на мировом рынке; 
- чрезмерная сложность новых финансовых инструментов, которые сопровождали стимул к разрушению.

Практический результат «мозговой атаки»- постулат о том, что мир в настоящее время испытывает необходимость коренного изменения экономической парадигмы, и надо искать новые пути создания новой глобальной финансовой системы (Что случилось ..., 2009).

Трудно не согласиться с выводами молодых лидеров. Они правы в том, что современный мир, общество, экономика перешли на новый виток развития, который уже характеризуется невероятной изменчивостью и нестабильностью. Отсюда и вполне понятная в силу этих особенностей непредсказуемость многих явлений, и притом в различных областях. Указывая на эти процессы, авторы известной книги «Глобальный кризис. За гранью очевидного» пишут: «В мире действуют неизученные силы. С виду все кажется вполне нормальным, как будто ничего не изменилось. Но на самом деле происходят необъяснимые вещи. Возможно, совсем скоро - завтра или послезавтра - невидимые, но важнейшие перемены внезапно станут очевидными, оказав огромное влияние на нашу жизнь. Однако, если мы не исследуем скрытую часть этого айсберга как можно быстрее, в один момент она сама выйдет на поверхность, и уже будет слишком поздно» (Райх, Аолан, 2010: 28).

Это касается и Казахстана, который, будучи интегрированным в мировую экономику, оказался, как и многие страны мира, втянутым в мировой экономический кризис. Поэтому Казахстан, как и многие пострадавшие от этого кризиса страны, ищет эффективные пути выхода из него. Можно напомнить несколько принципов из области политического руководства, умело использованных и используемых выдающимися руководителями в процессе реформирования и модернизации своей страны. Первое - это порядок, четкая постановка целей, отказ от всякого рода демагогий, второе - это всегда тщательный анализ средств для достижения указанных задач, минимизация затрачиваемых средств и усилий, третье - ясное понимание того, что решение этих задач требует мобилизации всех имеющийхся сил и средств. Понимание того, что решение масштабных задач государства невозможно без собранности, мобилизации и самоограничения. И как следствие - «отторжение системой институтов и лиц, доказывающих свою некомпетентность или бесполезность» (Иноземцев, 2008: Электронный ресурс). И четвертое - это устанавливаемый ими жесткий порядок, ибо без него нельзя обеспечить эффективность в условиях модернизации, это очень важное средство реализации плана реформирования и модернизации общества.

\section{СПИСОК АИТЕРАТУРЫ}

Аннан, К. (2000) Мы, народы: роль Организации Объединенных Наций в XXI веке : доклад Генерального секретаря // Коммерсантъ. №57. 4 апреля. С. 11.

Берентаев, К. Б. (2013) Экономика Казахстана и вызовы XXI века : сб. науч. трудов / под общ. ред. Б. К. Султанова. Алматы : КИСИ при Президенте РК. 244 с.

Гроф, С. (1992) За пределами мозга: рождение, смерть и трансценденция в психотерапии. М. : Центр «Соцветие». 335 с.

Иноземцев, В. А. (2008) Призыв к порядку [Электронный ресурс]// Российская газета. Федеральный выпуск № 4762. 1 октября. URL: http://rg.ru/2008/10/01/modernizatciya.html [архивировано в WebCite] (дата обращения: 12.09.2015).

Концепция целостности: критика буржуазной методологии науки (1987) / И. З. Цехмистро, В. И. Штанько, А. В. Тягло и др. Харьков : Вища школа, изд-во при Харьк. гос. ун-те. 223 с.

Кун, Т. С. (1975) Структура научных революций. М. : Прогресс. 288 с. 
Митрошенков, О. (2011) Цивилизационные вызовы и управленческие ответы в начале XXI века // Свободная мысль. №5. С. 191-202.

Моисеев, А. А. (2006) Международные финансовые организации. Правовые аспекты деятельности. М. : Омега $\Lambda .296$ с.

Моисеев, А. А. (2015) Природа глобализации и развитие международного сообщества // Право и государство. № 2 (67). С. 55-62.

Райх, М., Аолан, С. (2010) Глобальный кризис. За гранью очевидного : пер. с англ. М. : Претекст. 416 с.

Рассел, П. (2005) От науки к Богу. Путешествие физика в тайны сознания : пер. с англ. М. : Издательский АОС «София». 176 с.

Рубль пошел в последний путь (2014) / С. Аемура, А. Волчек : интервью [Электронный ресурс]// Радио Свободы. 6 декабря. URL: http://svoboda.org/content/article/26729113.html [apхивировано в WebCite] (дата обращения: 12.09.2015).

Следзевский, И. В. (2011) Аиалог цивилизаций как смысловое поле мировой политики // Общественные науки и современность. № 2. С. 141-156.

Сорос, Аж. (1999) Кризис мирового капитализма. Открытое общество в опасности : пер. с англ. М. : ИНФРА-М. 262 с.

Хайек, Ф. А. (1992) Пагубная самонадеянность. М. : Новости. 304 с.

Что случилось с мировой экономикой? «Мозговой штурм» молодых лидеров. (2009)// Международная экономика. № 3. С. 22-23.

Аата поступления: 11.11.2015 г.

\section{THE METHODOLOGICAL CRISIS OF SOCIAL SCIENCES IN THE CONTEXT OF CONTEMPORARY CHALLENGES \\ S. B. BULEKBAYEV}

(KazakH Ablai Khan University of International Relations and World Languages, Almaty)

Issues of research methodology have always been important for social sciences. In the contemporary world, globalizational challenges and economic crises both change the society dramatically and reveal the weakness of the explanatory capability of many conventional theories. Thus examining the theoretical and methodological foundations of contemporary social science proves a highly important challenge.

In our opinion, substantiated in the article, many underlying reasons for the contemporary systemic crisis have arisen because many fundamental concepts in social sciences fail to adequately reflect the changing reality, including the crises in global economy, politics and interethnic relations. Social sciences often can neither predict these processes nor explain their causes and nature.

We contend that the weakness of the explanatory capability of social science is due to its being founded on the Newtonian-Cartesian metaparadigm, which, in its turn, rests upon the laws of the macrocosm - while the contemporary world has actually become akin to a microcosm.

We conclude that the existing categorical apparatus needs reviewing and refining, which will consequently lead to a development of a new metaparadigm of thinking.

Keywords: methodology of social sciences; globalization; explanatory capability; paradigm; metaparadigm; global economy; global politics

\section{REFERENCES}

Annan, K. (2000) My, narody: rol' Organizatsii Ob»edinennykh Natsii v XXI veke [We the Peoples: The role of the United Nations in the 21st Century] : A report by the Secretary General. Kommersant», no. 57, April 4, p. 11. (In Russ.).

Berentaev, K. B. (2013) Ekonomika Kazakbstana i vyzovy XXI veka [The economy of Kazakhstan and the challenges of the 21st century] / ed. by B. K. Sultanov. Almaty, Kazakhstan Institute for Strategic Studies under the President of Kazakhstan Publ. 244 p. (In Russ.). 
Grof, S. (1992) Za predelami mozga: rozbdenie, smert' $i$ transtsendentsiia $v$ psikboterapii [Beyond the brain: Birth, death, and transcendence in psychotherapy]. Moscow, Tsentr "Sotsvetie" Publ. 335 p. (In Russ.).

Inozemtsev, V. L. (2008) Prizyv k poriadku [A call for order]. Rossiiskaia gazeta, no. 4762, October 1. [online] Available at: http://rg.ru/2008/10/01/modernizatciya.html [archived in Web Cite] (accessed 12.09.2015). (In Russ.).

Kontseptsiia tselostnosti: kritika burzbuaznoi metodologii nauki [A conception of integrity: Criticism of the bourgeois methodology of science] (1987) / I. Z. Tsekhmistro, V. I. Shtan'ko, A. V. Tiaglo et al. Kharkov, Vishcha shkola Publ. at Kharkov State University. 223 p. (In Russ.).

Kuhn, T. S. (1975) Struktura nauchnykb revoliutsii [The structure of scientific revolutions]. Moscow, Progress Publ. 288 p. (In Russ.).

Mitroshenkov, O. (2011) Tsivilizatsionnye vyzovy i upravlencheskie otvety v nachale XXI veka [Civilizational challenges and managerial responses at the start of the 21st century]. Svobodnaia mysl', no. 5, pp. 191-202. (In Russ.).

Moiseev, A. A. (2006) Mezbdunarodnye finansovye organizatsii. Pravovye aspekty deiatel'nosti [Global financial institutions. Legal aspects of their work]. Moscow, Omega L Publ. 296 p. (In Russ.).

Moiseev, A. A. (2015) Priroda globalizatsii i razvitie mezhdunarodnogo soobshchestva [The natu-re of globalization and the development of global community]. Pravo $i$ gosudarstvo, no. 2 (67), pp. 55-62. (In Russ.).

Raich, M. and Dolan, S. (2010) Global' nyi krizis. Za gran' iu ochevidnogo [Beyond: Business and society in transformation]. Moscow, Pretekst Publ. 416 p. (In Russ.).

Russell, P. (2005) Ot nauki k Bogu. Puteshestvie fizika v tainy soznaniia [From science to God: A physicist's journey into the mystery of consciousness]. Moscow, Sofia Publ. 176 p. (In Russ.).

Rubl' poshel v poslednii put' [Ruble has set off on its final journey] (2014) / S. Demura and D. Volchek : interview. Radio Svobody, December 6. [online] Available at: http://svoboda.org/content/article/26729113.html [archived in WebCite] (accessed 12.09.2015). (In Russ.).

Sledzevskii, I. V. (2011) Dialog tsivilizatsii kak smyslovoe pole mirovoi politiki [Dialogue between civilizations as a space of meanings in the world of global politics]. Obshchestvennye nauki $i$ sovremennost', no. 2, pp. 141-156. (In Russ.).

Soros, G. (1999) Krizis mirovogo kapitalizma. Otkrytoe obshchestvo v opasnosti [The crisis of global capitalism: Open society endangered]. Moscow, INFRA-M Publ. XXVI, 262 p. (In Russ.).

Hayek, F. A. (1992) Pagubnaia samonadeiannost' [The fatal conceit]. Moscow, Novosti Publ. 304 p. (In Russ.).

Chto sluchilos' s mirovoi ekonomikoi? «Mozgovoi shturm» molodykh liderov [What happened to the world economy? "Brainstorm" of young leaders]. (2009) Mezbdunarodnaia ekonomika, no. 3, pp. 22-23. (In Russ.).

Submission date: 11.11.2015.

Булекбаев Сагади Байузакович - доктор философских наук, профессор, профессор кафедры международных отношений Казахского университета международных отношений и мировых языков им. Абылай хана. Адрес: 050022, Казахстан, г. Алма-Ата, ул. Муратбаева, д. 200. Тел.: 8-10-7-7272-920805, внутр.315.Эл. aдрес: sagadi58@mail.ru

Bulekbayev Sagadi Bayuzakovich, Doctor of Philosophy, Professor, Department of International Relations, Kazakh Ablai Khan University of International Relations and World Languages. Postal address: 200 Muratbayev St., 050022 Almaty, Kazakhstan. Tel.: 8-10-7-7272-920805, int. 315. E-mail: sagadi58@mail.ru 